\title{
O DIÁLOGO E A TOLERÂNCIA NO ENSINO RELIGIOSO COMO FATORES CONTRIBUINTES PARA A CULTURA DA PAZ
}

\author{
Angélica Ferreira Ribeiro, Augusta Boa Sorte O. Klebis, Olga Maria de Andrade P. Boscoli \\ Universidade do Oeste Paulista - UNOESTE, FACLEPP, Curso de Pedagogia, Presidente Prudente, SP. E-mail: \\ arturshalom@hotmail.com.br
}

\section{RESUMO}

Este artigo apresenta as reflexões de uma pesquisa sobre o ensino religioso, pautado no diálogo e na tolerância, como dois pontos consideráveis na busca pela paz. O estudo se justifica pela importância de uma ação educativa voltada para a formação humana e cidadã. Para tanto, parte do pressuposto que a paz deve permear o meio no qual o indivíduo está inserido, assumindo assim relevância o debate sobre a importância de um despertar para o desenvolvimento da cultura da paz. Trata-se de uma pesquisa bibliográfica, de abordagem qualitativa que delineou como objetivo geral discutir a contribuição do diálogo e da tolerância no ensino religioso e no processo educacional como fatores contribuintes para a cultura da paz. Mais especificamente, se propôs a: a) apresentar o ensino religioso e sua contribuição para uma educação em valores; b) refletir sobre o papel do professor de ensino religioso e a importância do diálogo e da tolerância na tarefa de educar para a cultura da paz.

Palavras - chave: Ensino Religioso. Diálogo. Tolerância. Cultura da Paz.

\section{DIALOGUE AND TOLERANCE IN RELIGIOUS EDUCATION AS FACTORS CONTRIBUTORS TO THE CULTURE OF PEACE}

\begin{abstract}
This article presents the reflections of a research on religious education, based on dialogue and tolerance, as two significant points in the quest for peace. The study is justified by the importance of educational activities focused on human and civic education. To do so, it assumes that peace should permeate the environment in which the individual is inserted, thus taking important debate about the importance of an awakening to the development of the culture of peace. It is a bibliographical research, qualitative approach which outlined the general objective to discuss the dialogue and tolerance contribution to religious education and in the educational process as contributing factors to the culture of peace. More specifically, it was proposed to: a) provide religious education and its contribution to an education in values; $b$ ) reflect on the role of religious education teacher and the importance of dialogue and tolerance in the task of educating for a culture of peace.
\end{abstract}

Keywords: Religious Education. Dialogue . Tolerance. Culture of Peace 


\section{INTRODUÇÃO/OBJETIVOS}

Esta pesquisa busca enfatizar a importância do diálogo e da tolerância, juntamente com o ensino religioso como fatores importantes para que se caminhe em direção a cultura da paz e, consequentemente, a uma formação cidadã e humana. Parte do pressuposto que o diálogo e a tolerância são fatores importantes para a busca da cultura da paz, e que em toda e qualquer forma de convívio humano é preciso prezar por situações que conduzam o indivíduo a um bom relacionamento. Nesse sentido, entende como necessária a reflexão sobre o conteúdo dos quatro Pilares da Educação, propostos pela UNESCO: “[...] aprender a conhecer, aprender a fazer; aprender a viver juntos; aprender a ser" (DELORS, 2006, p. 90).

Da mesma forma, apresenta como relevante a reflexão sobre o ensino religioso, compreendido numa perspectiva antropológica-cultural, conforme define Ruedell (2005), uma vez que atende a necessidade de todo ser humano de se desenvolver plenamente e de buscar valores que orientem a sua existência.

Para tanto, este artigo apresenta um estudo sobre o ensino religioso e sua importância no desenvolvimento de conhecimentos e valores que oportunizam ao ser humano valorizar a vida, entender o próximo e ser responsável pelas próprias atitudes, da sua comunidade e do seu espaço, portanto, na formação integral do indivíduo, pautada em valores éticos e morais.

Para o seu desenvolvimento, delineou como objetivo geral discutir o diálogo e a tolerância no ensino religioso e no processo educacional como fatores contribuintes para a cultura da paz. Mais especificamente, se propôs a: descrever parte do conceito do ensino religioso para a sociedade atual e sua necessidade para uma educação em valores; refletir sobre a importância do diálogo e da tolerância na tarefa de educar.

\section{METODOLOGIA}

Trata-se de uma pesquisa de abordagem qualitativa, cuja opção metodológica foi pela pesquisa bibliográfica que buscou incursionar na produção de alguns autores que discutem o tema, bem como na legislação e documentos oficiais pertinentes.

Para Lakatos e Marconi (1999, p. 43, 44), o universo de uma pesquisa depende do assunto a ser investigado, e a amostra, porção ou parcela do universo, que realmente será submetida à verificação. $\mathrm{O}$ autor ressalta ainda a importância de se delimitar a pesquisa, ou seja, é estabelecer um recorte para a investigação. 
Os autores alertam de que não é possível a um indivíduo dominar a totalidade do assunto pesquisado, seria necessário selecionar o que pode ser tratado com profundidade, sendo assim, este artigo não tem por presunção o desejo de esclarecer totalmente o tema proposto.

Assim, com base em pesquisas de autores diversos que apresentam os fundamentos filosóficos, pedagógicos e legais do ensino religioso, esse estudo busca discutir a importância desse ensino para a construção de uma sociedade que valorize o diálogo e a tolerância como promotores da cultura da paz.

\section{O ENSINO RELIGIOSO E SUA RELEVÂNCIA}

Atualmente o ensino religioso na educação básica abre novas perspectivas, de forma que se desenvolva respeitando as diferentes crenças e convicções religiosas, se colocando à serviço das mais profundas aspirações humanas (RUEDELL, 2005).

Dessa forma, Pecine (2004), ressalta a importância da Lei nº 9.475, de 22 de julho de 1997 que dá nova redação ao art. 33 da Lei de Diretrizes e Bases da Educação Nacional (LDBEN), Lei $\mathrm{n}^{\circ}$. 9.394, de 20 de dezembro de 1996 com o objetivo de contextualizar o ensino religioso com a realidade sociocultural do Brasil. ao definir que:

Art. 33. O ensino religioso, de matrícula facultativa, é parte integrante da formação básica do cidadão e constitui disciplina dos horários normais das escolas públicas de ensino fundamental, assegurado o respeito à diversidade cultural religiosa do Brasil, vedadas quaisquer formas de proselitismo. $\S 1$ o Os sistemas de ensino regulamentarão os procedimentos para a definição dos conteúdos do ensino religioso e estabelecerão as normas para a habilitação e admissão dos professores. § 2ㅇ Os sistemas de ensino ouvirão entidade civil, constituída pelas diferentes denominações religiosas, para a definição dos conteúdos do ensino religioso.

A educação para desenvolver o homem em sua totalidade, não pode desconsiderar a dimensão da religiosidade, uma vez que "para a maioria dos povos, a religião não é um componente entre tantos outros de sua cultura, mas o núcleo inspirador de sua cosmovisão; é como a alma das culturas" (BERTONI, 2009, p. 164)

Para Bertoni (2009) a convivência com a diversidade religiosa é uma realidade do mundo moderno. Portanto, é fundamental que essa convivência vá além da tolerância, e se paute no respeito mútuo, na partilha de valores construtivos e "no reconhecimento da qualidade da busca religiosa do outro" (p. 168). Nesse sentido, torna-se necessária uma reflexão, mesmo breve, sobre a importância do professor de ensino religioso. 


\section{O PROFESSOR DE ENSINO RELIGIOSO E SUA PRÁTICA}

Pequenas atitudes fazem grande diferença na prática do professor de ensino religioso que deve ter como um dos principais objetivos a promoção da paz, não somente no ambiente educacional, mas também na comunidade escolar e no meio social como um todo. Assim, ele precisa viver e aplicar o que ensina, uma vez que com o seu exemplo ele conseguirá atingir de forma muito mais significativa seus educandos. Conforme Moreno (2005, p. 86)

O educador precisa caminhar em paz. Pode começar por pequenos passos: um aceitar a si mesmo, uma reconciliação, um perdão, uma confissão, uma aproximação carinhosa, um serviço delicado, uma paciência ou um presente, uma palavra e um diálogo, uma denuncia limpa, uma luta corajosa. Porque mais vale um gesto pacífico do que muitos discursos sobre a paz. Um gesto a cada dia, até terminar este ano; e, depois mais uma etapa...é um caminho sem fim, mas com os nossos gestos no mundo, certamente haverá mais paz.

No entanto, Pecini (2004, p. 89) nos revela em seus estudos certo grau de dificuldade que há na relação professor/aluno, na metodologia e na função da escola "na busca de coerência entre o que se pensa estar fazendo e o que realmente se faz". Nessa mesma linha de pensamento, o Referencial Curricular Nacional para a Educação Infantil (1998, p. 51) ressalta que:

A falta de coerência entre o discurso e a prática é um dos fatores que promove o fracasso do trabalho com os valores. Nesse sentido, dar o exemplo evidencia que é possível agir de acordo com valores determinados. Do contrário, os valores tornam-se vazios de sentido e aproximam-se mais de uma utopia não realizável do que de uma realidade possível.

Para Pecini (2004) o grande desafio no trabalho pedagógico consiste em ir além de ajudar o educando a alcançar uma maior autonomia na construção do saber, ou seja, deverá ensinar que ele tem uma identidade própria e, portanto, é único. Freire (apud PECINI, 2001, p. 106) apresenta uma reflexão muito importante sobre a postura do professor

Me movo como educador porque, primeiro, me movo como gente [...]. Sou gente. Sei que ignoro e sei que sei. Por isso, tanto posso saber o que ainda não sei como posso saber melhor o que já sei. E saberei tão melhor e mais autenticamente quanto mais eficazmente construo a minha autonomia em respeito à dos outros.

Na citação acima, há uma exortação ao homem, que nos leva a entender que ninguém sabe tudo, que qualquer um pode errar ou não conhecer algo e que é possível aprender melhor a cada dia construindo a autonomia em relação aos outros.

Esta postura é imprescindível na educação para a paz que de acordo com Moreno (2005, p. 
Uma educação para a paz faz parte, portanto, do desenvolvimento global da personalidade dos alunos e das alunas e não pode limitar-se a uma simples aprendizagem ocasional de conhecimentos ou de receitas de comportamento externo; deve ser uma educação transformadora e enriquecedora de valores e atitudes profundas.

O educador de ensino religioso, ou de qualquer outra disciplina, deve propiciar situações nas quais o aluno possa se conhecer melhor, perceber a importância de respeitar valores, compreender que apesar de cada indivíduo ser único é preciso saber viver em comunidade, com a diversidade humana em todas as suas dimensões. Dessa forma, haverá no aluno, uma maior compreensão quanto aos princípios éticos e morais.

Portanto, não se pode desconsiderar a importância de o professor de ensino religioso receber uma formação sólida e consistente, em nível superior, ou seja, o mesmo grau de formação exigido para a docência nas demais áreas. Da mesma forma, a exigência de uma formação continuada, pleiteando-se inclusive acesso a cursos de graduação e pós-graduação na área, voltada para uma perspectiva antropológica-cultural (RUEDELL, 2005). Assim, segundo o autor, espera-se que o professor de ensino religioso seja capaz de promover a abertura para a alteridade, para o diálogo, o respeito mútuo e, consequentemente, para o exercício pleno da cidadania.

De acordo com Puig (1998) quando se vive afastado da ética ou fora dela se está fora dos princípios que norteiam o homem e a sociedade. O autor afirma que quando se ensina deve-se considerar e respeitar a realidade e as experiências de cada aluno, e entender que o ensino consiste também na formação moral do educando, não do ponto de vista da imposição de valores, pois se entende que nenhum conhecimento pode ser considerado como verdade absoluta, mas da vivência e assimilação de valores pelos alunos, e estes podem recebê-los e ponderá-los por verdade em suas vidas. Puig (1998) ressalta ainda que a educação ética e moral propiciam uma análise crítica da realidade cotidiana e das normas sociomorais vigentes, de modo a buscar formas de convivência mais justas e democráticas.

O professor de ensino religioso poderá trazer uma contribuição significativa no processo de aprendizagem do educando, ao ser alguém que entende o diálogo como um aspecto fundamental na relação professor aluno. Caberá a ele apresentar "princípios orientadores que ajudarão o educando a descobrir o sentido da vida" (RUEDELL, 2005, p. 140), bem como promover um debate aberto e responsável a respeito da liberdade e da consciência dos alunos sobre os conteúdos e valores da sua religião e em relação a escolha livre e responsável.

Pecini (2004 p. 91) ajuda a compreender que o professor de ensino religioso é alguém que deve levar em consideração que a família e a vivência religiosa são espaços de muita importância, 
nesse aspecto, o educador deve colocar seu conhecimento e sua experiência pessoal a serviço da liberdade do aluno. Para tanto, deve propiciar o desenvolvimento da cidadania e garantir "o diálogo e a participação, para que, acima de tudo, a alteridade seja preservada de forma democrática e participativa e o Ensino Religioso consiga alcançar a sua meta principal, que é o sentimento antropológico/filosófico da religião, em ambiente escolar".

\section{O ensino religioso na busca de valores para a construção da cultura da paz}

A formação moral e ética é construída desde a infância, conforme Aristóteles (2006, p. 41) nos leva a refletir

É por esta razão que devemos atentar para a qualidade dos atos que praticamos, pois nossas disposições morais correspondem às diferenças entre nossas atividades. E não será desprezível a diferença se, desde a nossa infância, nos habitarmos desta ou daquela maneira, ao contrário, terá imensa importância, ou seja será decisiva (ARISTÓTELES, 2006, p.41).

Nessa perspectiva o ensino religioso tem uma contribuição relevante na formação de crianças e jovens. No entanto, para que se realize eficazmente, contribuindo para a formação de valores e a cultura da paz, é necessário que a escola tenha como meta principal o diálogo.

De acordo com Moreno (2005, p. 86) “Falar de educação para a paz é falar de uma educação baseada em valores." Dialogar, é um dos quesitos mais importantes para um bom relacionamento entre educador e aluno. Pecini (2004, p. 108), escreve a respeito da importância do diálogo dizendo:

Há necessidade de diálogo constante com a realidade cultura e social em que se vive, para manter seu serviço adaptado às exigências dos tempos. Toda proposta educativa é a proposta de uma pergunta educativa. Os jovens, adolescentes, as crianças, quando vêm a nós, fazem muitas perguntas. Pedem-nos cultura, alimentação, afeto, divertimento, fé. Muitas vezes não nos perguntam nada em particular, mas pedem simplesmente que se estabeleça um relacionamento conosco.

Ainda a respeito do dialogo, Moreno $(2005$, p. 87 ) diz que a educação para a paz tem que ser vivencial e realizada a partir da experiência, ou seja, da interação dinâmica e criativa. Nesse mesmo sentido Moreno (2005) ainda diz que só se podem educar para a paz quando quem educa já é pacificado interiormente, quando dialoga com sinceridade e quando se aproxima fraternalmente, quando abre as mãos com generosidade e quando rejeita toda e qualquer injustiça. Moreno (2005, p. 87) 
Enfim, educamos para a paz quando vivemos na fé consciente, madura e comprometida e lutamos pela verdade e pela justiça, quando vivemos em nossa vida a verdade e a justiça, quando vivemos a tarefa incansável de cada dia pela convivência, pela participação e pela comunidade. Porque a paz não é uma coisa pronta, é um contínuo fazer, é obra da justiça e do amor.

Segundo Pecini (2004, p. 109) "quem dialoga não impõe, propõe". Sendo assim, é importante que o educador respeite as escolhas religiosas dos alunos, buscando sempre promover a compreensão do homem a partir do ponto de vista individual, dentro dos princípios da ética, pois:

A ética deve sempre permear a condução dos diálogos interreligiosos, principalmente em um ambiente escolar com a diversidade de pessoas oriundas das mais diferentes classes sociais e culturas e que trazem consigo uma visão de mundo muito particular, que, no ambiente escolar, podem ser transformadas em conhecimento (PECINI, 2004, P. 109).

A transmissão de valores e da religião às novas gerações obedece aos padrões culturais, levando em conta também a influência dos fatores afetivos da família. Portanto, para aprender a conviver é preciso antes de tudo ajudar a criança e adolescente a "descobrir-se a si mesmos"(DELORS, 2006, p. 98). E complementa

Só então poderão, verdadeiramente, pôr-se no lugar dos outros e compreender as suas reações. Desenvolver esta atitude de empatia, na escola, é muito útil para os comportamentos sociais ao longo de toda a vida. Ensinando, por exemplo, aos jovens a adotar a perspectiva de outros grupos étnicos ou religiosos podem-se evitar incompreensões geradoras de ódio e violência entre adultos. Assim, o ensino de história das religiões ou dos costumes pode servir de referencia útil para futuros comportamentos.

Portanto, a prática pedagógica do ensino religioso implica na existência da tolerância e respeito às pessoas que possuem outras religiões ou pontos de vista diferentes do professor ou da maioria dos alunos. A tolerância é uma palavra chave nas relações entre as pessoas com suas diferentes crenças religiosas, nesse caso, pode-se dizer que é preciso saber conviver com e nas situações. Para Delors (2006, p.102) enfrentar os desafios do século XXI exige "aprender a viver juntos desenvolvendo a compreensão do outro e a percepção das interdependências - realizar projetos comuns e preparar-se para gerir conflitos - no respeito pelos valores de pluralismo, da compreensão mútua e da paz".

As diferenças sempre existirão na humanidade, vivenciar a cultura da paz "não significa necessariamente o desaparecimento das diferenças e das contradições, ou que não importa no 
que você acredita se é que acredita em alguma coisa. Uma atitude tolerante pode perfeitamente coexistir com uma sólida fé e com a tentativa de converter os outros" (PECINI, 2004, P. 110).

O ensino religioso precisa ser entendido não apenas como instrução para a formação moral, mas como construção de vida, uma prática diária de vivência, para que não fique somente na teoria, mas também num comprometimento com o próximo, com a vida e com a comunidade. Segundo Puig (1998), a educação moral é uma tarefa destinada a dar forma moral à própria identidade humana por meio de um trabalho de reflexão e ação que parte das circunstâncias que cada sujeito encontra no seu dia a dia. A escola pode trabalhar com seus alunos, temas que farão toda diferença para sua formação humana, tais como: "Verdade, Ação Correta (código Moral); Paz; Amor e Não Violência. Esses valores são à base de toda a filosofia de vida e nos permitem encontrar o fundamento do conceito da educação, pela qual todos deverão lutar" (PECINI, 2004, p 114).

É importante que haja compreensão para uma convivência pacificadora, conforme nos diz Faria (2013), é preciso aprender a se apoiar mutuamente; a olhar para o outro; a expressar compaixão e tolerância; a confiança, o respeito, a solidariedade e a cooperação no cotidiano, caminhando assim para uma concepção mais humana de cidadania.

Um bom cidadão reconhece que ele não vive isoladamente, que ele precisa do outro e consequentemente entender que suas ações implicarão também na vida do próximo; esse é o ponto de partida para a construção real de uma cultura para a paz, conforme diz Faria (2013, p. 65) "A consciência sobre os atos violentos que sofremos e cometemos é o ponto de partida para a construção real de uma cultura para a paz que atinja os níveis pessoais e coletivos em nossa convivência, uma tarefa inacabada, para a vida toda."

\section{CONSIDERAÇÕES FINAIS}

Entende-se que o diálogo e a tolerância no ensino religioso e no processo educacional, assumem relevância para a busca da paz e se constituem características intrínsecas da formação humana e cidadã.

Para tanto, é imprescindível que o professor de ensino religioso, assim como os demais, seja capaz de estabelecer uma profunda coerência entre o que apregoa e a sua prática, bem como um diálogo permanente com os alunos, de forma a desenvolver atitudes de respeito mútuo e tolerância à diversidade, tendo a ética como parte essencial de todas as aulas.

Conclui-se que, a luta em favor da paz constitui um desafio não apenas para núcleos restritos de especialistas, mas um compromisso de todos para uma educação ampla e formadora 
de uma visão holística que aponte para uma sociedade mais fraterna e humana, que tenha como horizonte maior a cultura da paz.

\section{REFERÊNCIAS}

ARISTÓTELES. Ética a Nicômaco. Texto Integral, Editora Martin Claret, São Paulo, 2006.

BERTONI, José Carlos. O Ensino Religioso nas Escolas Públicas. In: Ciências da Religião - História e Sociedade , Volume 7 , N. 1 , 2009, PP. 150-173. Disponível em: http://editorarevistas.mackenzie.br/index.php/cr/article/viewFile/1129/847 Acesso: 20/05/2015.

BRASIL. Lei n. 9.475, 22 de julho de 1997. Dá nova redação ao art. 33 da Lei n.⒐394, de 20 de dezembro de 1996, que estabelece as Diretrizes e Bases da Educação Nacional. Lex: Diário Oficial da União, Brasília, DF: 1997.

Referencial Curricular Nacional para a Educação Infantil/ Ministério da Educação e do Desporto, Secretaria de Educação Fundamental. - Brasília: MEC/SEF, 1998.

DELORS, Jacques. Educação um tesouro a descobrir. 10 ed. São Paulo: Unesco, Cortez, 2006.

FARIA, H. (Coord.). Cultura Viva, políticas públicas e cultura de paz / Hamilton Faria, Pedro Benjamin Garcia, Valmir de Souza... et al. - São Paulo: Instituto Pólis, 2013.

MORENO, Ciriaco Izquierdo. Educar em valores. 3ạ edição. São Paulo. Editora Paulinas. 2005.

OLIVEIRA, Ednilson Turozi de. Ensino religioso fundamentos epistemológicos. 1 ed. Curitiba PR, intersaberes, 2012.

PECINI, José Claúdio. O Ensino Religioso e o seu Caráter Formador do Cidadão Contemporâneo. 2004. 128p. Dissertação (Mestrado em Educação) - Pró-Reitoria da Pesquisa e Pós-Graduação, Universidade do Oeste Paulista - Unoeste, Presidente Prudente, 2004.

PUIG, Josep Maria. A construção da personalidade moral. 1. ed. São Paulo. Editora Ática, 1998.

RUEDELL, Pedro. Fundamentação antropológico-cultural da religião segundo Paul Tillich Perspectivas pedagógicas aberta frente aos dispositivos legais vigentes. 2005. 183p. Tese (Doutorado em Educação) - Programa de Pós-Graduação em Educação do Centro de Ciências Humanas da Universidade do Vale do Rio dos Sinos. Unisinos, São Leopoldo, 2005. 